\title{
Left Atrial Appendage (LAA) Function by Transesophageal Echocardiography before and after Percutaneous Balloon Mitral Valvuloplasty (PBMV)- A Comparative Study
}

\author{
Satyendra Kumar A ${ }^{\circledR 1}$, Magesh B ${ }^{\circledR 2}$ \\ ${ }^{1}$ Assistant Professor, Department of Cardiology, GSL Medical College, Rajahmundry, Andhra Pradesh, India, ${ }^{2}$ Assistant Professor, Department of Cardiology, Sapthagiri \\ Institute of Medical Sciences \& Research Centre, Bangalore, Karnataka, India.
}

\section{Abstract}

Background: In the past, the left atrial appendage (LAA) has been considered to be a relatively insignificant portion of cardiac anatomy. It is now recognized that it is a structure with important pathological associations. First, thrombus has a predilection to form within the LAA in patients with non-valvar atrial fibrillation and to a lesser extent in those with mitral valve disease (both in atrial fibrillation and in sinus rhythm). Second, the use of transoesophageal echocardiography has made clear imaging of the LAA possible, so that its size, shape, flow pattern, and content can be assessed in health and disease. Subjects and Methods: This study population consisted of 40 patients with symptomatic mitral stenosis who underwent percutaneous mitral balloon valvotomy in the cardiology department of GSL medical college, Rajahmundry over a time period of 1 April 2017 to 30 March2018. Patients in all age groups, with evidence of severe MS (MVA $<1.0 \mathrm{~cm}^{2}$ ) admitted in our institution, in whom PBMV was feasible were included. Those who were fulfilling the PBMV intervention criteria and those who had good results only were included. Results: Left atrial appendage late emptying velocity, LAALF: Left atrial appendage late filling velocity Spontaneous echocontrast (SEC) was present in 10 of the 40 patients before a procedure but completely disappeared ( 6 patients) or decreased (4 patients) after the procedure. LAALE \& LAALF velocities measured by Doppler were increased significantly after PBMV and at 6 months follow up compared with baseline $(\mathrm{P}<0.001)$. Conclusion: Successful Percutaneous balloon mitral valvotomy decreases the intensity of spontaneous LA contrast, reduces the size of the LA, and improves LA and LAA function. Relief of MS may confer not only hemodynamic benefits for improvement of symptoms but also have a favorable influence on future thromboembolism.

Keywords: Rheumatic Mitral Stenosis, Left Atrial Thrombus, Thromboembolism, Transesophageal Echocardiography

Corresponding Author: Magesh B, Assistant Professor, Department of Cardiology, Sapthagiri Institute of Medical Sciences \& Research Centre, Bangalore, Karnataka, India.

E-mail: drbmagesh@gmail.com

Received: 29 March 2020

\section{Introduction}

Rheumatic mitral stenosis (MS) is a frequent cause of valve disease in developing countries. In Western countries, it remains a significant problem, despite the striking decrease in the prevalence of rheumatic fever and still accounts for $12 \%$ of native valvular heart disease. ${ }^{[1]}$ In the past, the left atrial appendage (LAA) has been considered to be a relatively insignificant portion of cardiac anatomy. It is now recognized that it is a structure with important pathological associations. ${ }^{[2]}$ First, thrombus has a predilection to form within the LAA in patients with non-valvar atrial fibrillation and to a lesser extent in those with mitral valve disease (both in atrial fibrillation and in sinus rhythm). Second, the use of transesophageal echocardiography has made clear imaging of the LAA possible, so that its size, shape, flow pattern, and content can be assessed in health and disease. The risk of stroke is increased approximately fivefold in non-rheumatic atrial fibrillation and 17-fold in patients with mitral stenosis

and atrial fibrillation. ${ }^{[3,4]}$ About $15 \%$ of ischemic strokes arise as a result of atrial fibrillation. ${ }^{[5]}$ Approximately $90 \%$ of atrial thrombi in non-rheumatic atrial fibrillation and $60 \%$ of such thrombi in patients with rheumatic mitral valve disease (predominantly stenosis) are seen within the LAA. ${ }^{[6]}$ Although the incidence of thromboembolism in atrial fibrillation and mitral valve disease can be dramatically reduced with the use of anticoagulants, particularly Warfarin, the use of such treatment can be complicated, and is 
contraindicated in many patients. ${ }^{[7]}$ Reduced left atrial (LA) appendage (LAA) function can be a cause for stroke in patients within sinus rhythm even in the absence of mitral valve disease. ${ }^{[8]} \mathrm{A}$ subset of mitral stenosis (MS) in sinus rhythm at increased risk of embolization can be indicated by a Doppler transesophageal echocardiographic (TEE) LAA flow profile. ${ }^{[9]}$ One of the factors implicated in the development of the thrombus is stasis in LA and LAA, observed as a reduction in blood flow velocity. ${ }^{[10,11]}$ Stasis in blood flow in a patient with chronic MS occurs concomitantly with a reduction in wall movement. Both the magnitude and the pattern of LAA emptying and filling velocities are dependent on loading conditions, and LAA function is influenced to a greater extent by changes in left ventricular function. ${ }^{[12]}$ Doppler tissue imaging (DTI) is a new ultrasonographic technique based on the Doppler principle that allows quantification of intramural myocardial velocities by detection of consecutive phase shift of the ultrasound signal reflected from contracting myocardium. ${ }^{[13]}$ LAA Doppler tissue velocities have been shown to decrease in patients with MS even though in sinus rhythm. ${ }^{[14,15]}$

Since its introduction in 1984 by Inoue et al, ${ }^{[16]}$ percutaneous balloon mitral valvotomy (PBMV) has become established as a safe and effective treatment for rheumatic mitral stenosis with results equivalent to surgical valvotomy. ${ }^{[17-19]}$ Commissural splitting is the dominant mechanism by which the mitral valve area is increased during balloon dilatation. ${ }^{[20-22]}$ However, the changes in LAA function of patients with MS after percutaneous balloon mitral valvuloplasty (PBMV) have very few studies so far. Therefore the aim of this study was to compare left atrial appendage (LAA) function by transesophageal cardiography before and after percutaneous balloon mitral valvuloplasty (PBMV).

\section{Subjects and Methods}

This study population consisted of 40 patients with symptomatic mitral stenosis who underwent percutaneous mitral balloon valvotomy in the cardiology department of GSL medical college, Rajahmundry over a time period of 1 April 2017 to 30 March2018. Patients in all age groups, with evidence of severe MS (MVA $<1.0 \mathrm{~cm}^{2}$ ) admitted in our institution, in whom PBMV was feasible were included. Those who were fulfilling the PBMV intervention criteria and those who had good result only were included, while the patients with left atrial thrombus, Mitral regurgitation greater than 2/4, Calcific mitral valve leaflets and commissures, Severe aortic valve disease associated with mitral stenosis, Critically ill patients and patients in New York Heart Association Functional Class IV, Patients with atrial fibrillation, Pregnancy, Failure to give informed consent, Patients who had hypertension, diabetes mellitus, congenital heart disease, left ventricular systolic dysfunction or history of myocardial infarction and emergency percutaneous mitral balloon valvotomy were excluded from the study. All participants gave their informed consent and our institutional ethical committee approved the study protocol. After informed consent, all patients underwent a detailed clinical evaluation as per our proforma. All the patients were asked to refrain from oral water and food intake for at least 4 hours. An appropriate position with a peripheral venous line was obtained before the procedure. Electrocardiographic (ECG) monitoring was performed and arterial saturation was monitored by pulse oximetry during TEE examination. Using a 5 $\mathrm{MHz}$ multiplane transesophageal probe, TEE was performed. Throughout the study, ECG was recorded continuously. Topical lidocaine spray was used to anesthetize the oropharynx. The TEE probe was swallowed after adequate topical anesthesia and sedation. Routine TEE measurements were made completely.Statistical analysis was performed with SPSS version 13.0. Data were presented as mean \pm SD for continuous variables and as percentages for categorical variables, parametric continuous variables were tested with paired sample t-test. A P value less than 0.05 was considered to indicate statistical significance. Trends for continuous variables over 6 months were assessed using Friedman's test.

\section{Results}

All patients except two had dilated LA $(>40 \mathrm{~mm})$. LA size ranged from $36-60 \mathrm{~mm}$. Mean LA size was $46.40 \pm 4.70 \mathrm{~mm}$.

\section{Left ventricular function:}

All patients had adequate LV function ( $>50 \%)$. Mean Ejection Fraction was $60.61 \pm 5.65 \%$.

\section{Wilkins Score:}

It ranged from 5-9. Mean score was 6.02 \pm 0.84 .

\section{D assessment of mitral valve}

Mean 2D MVA was $0.85 \pm 0.14 \mathrm{~cm}^{2}$ (range $0.60-1.10 \mathrm{~cm}^{2}$ ) before PBMV and significantly increased to $1.71 \pm 0.16 \mathrm{~cm}^{2}$ (range $1.40-2.10 \mathrm{~cm}^{2} ; \mathrm{P}=0.0001$ ) after PBMV. Peak gradient \& mean gradient before PBMV $(31.12 \pm 8.28 \mathrm{~mm} \mathrm{Hg}$, $20.41 \pm 6.44 \mathrm{~mm} \mathrm{Hg}$ ) were significantly decreased after PBMV $(9.27 \pm 1.94 \mathrm{~mm} \mathrm{Hg}, 5.17 \pm 1.17 \mathrm{~mm} \mathrm{Hg})$ respectively . A good valve opening was observed in all patients.

\section{Mitral regurgitation}

Trivial to mild mitral regurgitation (MR) was seen in $(<2 / 4$ grade MR) 12 (30\%) cases.

LAALE: Left atrial appendage late emptying velocity, LAALF: Left atrial appendage late filling velocity Spontaneous echocontrast (SEC) was present in 10 of the 40 patients before a procedure but completely disappeared ( 6 patients) or decreased (4 patients) after the procedure. LAALE \& LAALF velocities measured by Doppler were increased significantly 


\begin{tabular}{ll}
\hline Table 1: Baseline Characteristics of the population & \\
\hline Characteristics & Patients \\
\hline Age & $29 \pm 1.0 \mathrm{yrs}$ \\
\hline Sex & $11(27 \%)$ \\
\hline Male & $29(73 \%)$ \\
\hline Female & $21.45 \pm 18.45$ months \\
\hline Duration of symptoms & \\
Functional class (NYHA) & 0 \\
Class I & $16(40 \%)$ \\
Class II & $24(60 \%)$ \\
Class III & 0 \\
Class IV & \\
\hline Rheumatic fever History & $10(25 \%)$ \\
Present & $30(75) \%$ \\
\hline Absent & 0 \\
\hline CVA History & 0 \\
\hline Atrial fibrillation & $155.32 \pm 9.81 \mathrm{~cm}$ \\
\hline Height & $46.40 \pm 4.70 \mathrm{~mm}$ \\
\hline LA size & 0 \\
\hline Left ventricular dysfunction & $60.61 \pm 5.65 \%$ \\
Left ventricular ejection fraction & $6.02 \pm 0.84$ \\
\hline Wilkins score & \\
\hline
\end{tabular}

Table 2: Comparison of LAA function before and after PBMV by TEE

\begin{tabular}{|c|c|c|c|c|c|}
\hline Parameter & BeforePTMC & AfterPTMC & At6months & $\begin{array}{l}\text { P- } \\
\text { value(beforeVs } \\
\text { after) PTMC }\end{array}$ & $\begin{array}{l}\text { P-value(AfterPTMC } \\
\text { Vs } 6 \text { month follow } \\
\text { up) }\end{array}$ \\
\hline LAALE, $\mathrm{cm} / \mathrm{s}$ & $23.19 \pm 7.73$ & $43.76 \pm 11.77$ & $46.53 \pm 12.58$ & $<0.001$ & $<0.001$ \\
\hline LAALF, $\mathrm{cm} / \mathrm{s}$ & $32.94 \pm 10.81$ & $41.61 \pm 11.73$ & $44.73 \pm 12.04$ & $<0.001$ & $<0.001$ \\
\hline $\mathrm{E}_{L A A,} \mathrm{~cm} / \mathrm{s}$ & $7.46 \pm 2.03$ & $11.12 \pm 2.47$ & $13.31 \pm 2.39$ & $<0.001$ & $<0.001$ \\
\hline $\mathrm{A}_{L A A,} \mathrm{~cm} / \mathrm{s}$ & $12.81 \pm 3.20$ & $24.68 \pm 5.02$ & $25.99 \pm 5.16$ & $<0.001$ & $<0.001$ \\
\hline $\mathrm{S}_{L A A,} \mathrm{~cm} / \mathrm{s}$ & $9.54 \pm 2.19$ & $17.54 \pm 2.62$ & $18.86 \pm 3.27$ & $<0.001$ & $<0.001$ \\
\hline
\end{tabular}

after PBMV and at 6 months follow up compared with baseline $(\mathrm{P}<0.001)$. ELAA, ALAA, SLAA wave values measured by DTI were found to be increased significantly after PBMV and at 6 months follow up compared with baseline $(\mathrm{p}<0.001)$ [Table2].

\section{Discussion}

The effect of PBMV on LAA functions has been investigated in various studies. Wang et al, ${ }^{[23]}$ showed the changes in LAA flow velocities and in SEC at the time of transient occlusion of the mitral valve by balloon inflation. LAA blood flow velocity reduces substantially even to the point of complete stasis resulting in acute enhancement of SEC to the highest grade almost simultaneously during the mechanical obstruction of blood flow by balloon inflation at the mitral valve. Upon balloon deflation, LAA blood flow velocity increases again, resulting in the reduction or disappearance of SEC within the same time interval and LAA emptying and filling velocities have increased after the procedure. ${ }^{[23]}$ Basal and postprocedure LAA velocities in patients with atrial fibrillation were found to be lower when compared with velocities in those with sinus rhythm. ${ }^{[23]}$ In the same study at peak balloon inflation, LAA velocities were significantly lower and SEC was significantly higher in a group with atrial fibrillation than in a group with sinus rhythm. Thus, regular 
contraction in sinus rhythm may decrease SEC formation.

Spontaneous echocardiographic contrast (SEC) or "smoke" in the left atrium (LA) is a pattern of increased blood echogenicity caused by ultrasonic backscatter from red blood cell aggregates. These aggregates form due to noncovalent binding between red cells and plasma proteins under low flow and low shear conditions. ${ }^{[24-26]}$ Spontaneous echo contrast is associated with clot formation and embolic phenomena. There is very little data on the significance of SEC in sinus rhythm (NSR). Spontaneous echo contrast was graded as 0 - no smoke, $1+-$ mild smoke visible in some portion of the LA, 2+dense smoke that appeared throughout the LA.27 Spontaneous echo contrast in NSR occurs in patients with significantly dilated LA and depressed atrial function. Left atrial thrombus is noted in $13 \%$ of such patients despite NSR. Spontaneous echo contrast in NSR is associated with a higher prevalence of CVA. ${ }^{[27]}$

In patients with mitral stenosis with normal sinus rhythm, Bernstein NE et al, ${ }^{[28]}$ found SEC in the echocardiograms of $21(45 \%)$ of 47 patients.In another study, Kasliwal RR et al, ${ }^{[29]}$ found that spontaneous echo contrast in the left atrium was seen in $57.3 \%$ of patients on multiplane transoesophageal echocardiography. In our study 10 patients had SEC. Among ten patients, 6 patients had grade $1+, 4$ patients had grade $2+$ before the procedure. After the procedure SEC disappeared in 6 patients who had grade $1+$. Remaining 4 patients who had grade $2+$ decreased to grade $1+$. Osman et al, ${ }^{[30]}$ studied 20 patients with mitral stenosis in sinus rhythm. Spontaneous echocontrast (SEC) was present in 7 of the 20 patients before the procedure but completely disappeared (4 patients) or decreased (3 patients) after the procedure. Rajesh Vijayvergiya et al, ${ }^{[31]}$ from PGI, Chandigarh, studied 47 patients with severe mitral stenosis before and after PBMV.They also noticed a significant improvement in SEC grading.

In a study conducted by Jean Marc Porte et al, ${ }^{[32]}$ thirtyseven consecutively admitted patients with severe mitral stenosis underwent percutaneous mitral commissurotomy with a transesophageal echocardiographic examination before and between 24 and 48 hours after percutaneous mitral commissurotomy. After commissurotomy, a marked increase in LAA peak Doppler velocity $(+62 \%)$ and in LAA velocity time integral $(+31 \%)$ was observed. The increase in peak Doppler velocity after commissurotomy was related to the decrease or regression in left atrial spontaneous echo contrast, and correlated with the increase in mitral valve area, the decrease in transmitral pressure gradient, and the increase in a cardiac index; improvement in valve function. Osman Karkaya et al, ${ }^{[30]}$ studied twenty patients with symptomatic rheumatic mitral stenosis before and after percutaneous balloon mitral valvotomy. They found that there was no significant difference in LAA late filling velocity and percent area change of LAA after PBMV. LAA late emptying velocity increased significantly after PBMV compared with baseline. In a study by Rajesh et al, ${ }^{[31]}$ they noticed significant changes in LAA late emptying and late filling velocities immediately and at 6 months after PBMV procedure.

\section{Conclusion}

Successful Percutaneous Balloon mitral valvotomy decreases the intensity of spontaneous LA contrast, reduces the size of the LA, and improves LA and LAA function. Relief of MS may confer not only hemodynamic benefits for improvement of symptoms but also have a favorable influence on future thromboembolism.

\section{References}

1. Lung B, Baron G, Butchart EG. A prospective survey of patients with valvular heart disease in Europe: The Euro Heart Survey on Valvular Heart Disease. Eur Heart J. 2003;24:1231-1243. Available from: https://dx.doi.org/10. 1016/s0195-668x(03)00201-x.

2. Blackshear JL, Odell JA. Appendage obliteration to reduce stroke in cardiac surgical patients with atrial fibrillation. Ann Thoracic Surg. 1996;61(2):755-759. Available from: https: //dx.doi.org/10.1016/0003-4975(95)00887-x.

3. Wolf PA, Abbott RD, Kannel WB. Atrial fibrillation as an independent risk factor for stroke: the Framingham Study. Stroke. 1991;22(8):983-988. Available from: https://dx.doi. org/10.1161/01.str.22.8.983.

4. Wolf PA, Dawber TR, Thomas HE, Kannel WB. Epidemiologic assessment of chronic atrial fibrillation and risk of stroke: The fiamingham Study. Neurol. 1978;28(10):973-973. Available from: https://dx.doi.org/10.1212/wnl.28.10.973.

5. Jannou V, Timsit S, Nowak E, Rouhart F, Goas P, Merrien FM. Stroke with atrial fibrillation or atrial flutter: a descriptive population-based study from the Brest stroke registry. BMC Geriatr. 2015;15:63. Available from: https://dx.doi.org/10. 1186/s12877-015-0067-3.

6. Odell JA, Blackshear JL, Davies E, Byrne WJ, Kollmorgen CF, Edwards WD, et al. Thoracoscopic obliteration of the left atrial appendage: Potential for stroke reduction? Ann Thoracic Surg. 1996;61(2):565-569. Available from: https://dx.doi.org/ 10.1016/0003-4975(95)00885-3.

7. Brass LM, Krumholz HM, Scinto JM, Radford M. Warfarin Use Among Patients With Atrial Fibrillation. Stroke. 1997;28(12):2382-2389. Available from: https://dx.doi.org/10. 1161/01.str.28.12.2382.

8. Kamalesh M, Copeland TB, Sawada S. Severely reduced left atrial appendage function: A cause of embolic stroke in patients in sinus rhythm? 1998;11(9):902-904. Available from: https://dx.doi.org/10. 1016/s0894-7317(98)70011-2.

9. Daimee MA, Salama AL, Cherian G, Hayat NJ, Sugathan TN. Left atrial appendage function in mitral stenosis: is a group in sinus rhythm at risk of thromboembolism? Int $\mathrm{J}$ Cardiol. 1998;66(1):45-54. Available from: https://dx.doi.org/10.1016/ s0167-5273(98)00128-4. 
10. Shively BK, Gelgand EA, Crawford MH. Regional left atrial stasis during fibrillation and flutter determinants and relation to stroke. J Am Coll Cardiol. 1996;27(7):1722-1729. Available from: https://dx.doi.org/10.1016/0735-1097(96)00049-6.

11. Goldman ME, Pearce LA, Hart RG, Zabalgoitia M, Asinger RW, Safford R, et al. Pathophysiologic Correlates of Thromboembolism in Nonvalvular Atrial Fibrillation: I. Reduced Flow Velocity in the Left Atrial Appendage (The Stroke Prevention in Atrial Fibrillation [SPAF-III] Study). J Am Soc Echocardiogr. 1999;12(12):1080-1087. Available from: https: //dx.doi.org/10.1016/s0894-7317(99)70105-7.

12. Hoit BD, Shao Y, Gabel M. Influence of acutely altered loading conditions on left atrial appendage flow velocities. J Am Coll Cardiol. 1994;24(4):1117-1123. Available from: https: //dx.doi.org/10.1016/0735-1097(94)90878-8.

13. McDicken WN, Sutherland GR, Moran CM, Gordon LN. Colour doppler velocity imaging of the myocardium. Ultrasound Med Biol. 1992;18(6-7):651-654. Available from: https: //dx.doi.org/10.1016/0301-5629(92)90080-t.

14. Topsakal R, Eryol NK, Ozdogru I, Seyfeli E, Abaci A, Oguzhan A, et al. Color Doppler Tissue Imaging to Evaluate Left Atrial Appendage Function in Patients With Mitral Stenosis in Sinus Rhythm. Echocardiogr. 2004;21(3):235-240. Available from: https://dx.doi.org/10.1111/j.0742-2822.2004.03077.x.

15. Gurlertop Y, Yilmaz M, Acikel M, Bozkurt E, Erol MK, Senocak H, et al. Tissue Doppler Properties of the Left Atrial Appendage in Patients with Mitral Valve Disease. Echocardiogr. 2004;21(4):319-324. Available from: https://dx. doi.org/10.1111/j.0742-2822.2004.03002.x.

16. Inoue $\mathrm{K}$, Owaki $\mathrm{T}$, Nakamura $\mathrm{T}$, Kitamura $\mathrm{F}$, Miyamoto $\mathrm{N}$. Clinical application of transvenous mitral commissurotomy by a new balloon catheter. J Thorac Cardiovasc Surg. 1984;87(3):394-402. Available from: https://dx.doi.org/10. 1016/s0022-5223(19)37390-8.

17. Farhat MB, Ayari M, Maatouk F, Betbout F, Gamra H, Jarrar M, et al. Percutaneous Balloon Versus Surgical Closed and Open Mitral Commissurotomy. Circulation. 1998;97(3):245-250. Available from: https://dx.doi.org/10.1161/01.cir.97.3.245.

18. Vahanian A, Michel PL, Cormier B, Vitoux B, Michel X, Slama $\mathrm{M}$, et al. Results of percutaneous mitral commissurotomy in 200 patients. Am J Cardiol. 1989;63(12):847-852. Available from: https://dx.doi.org/10.1016/0002-9149(89)90055-6.

19. Bassand J, Schiele F, Bernard Y. Double balloon and Inoue techniques in percutaneous mitral valvotomy: comparative results in a series of 232 cases. J Am Coll Cardiol. 1991;18:982-991.

20. Reid CL, McKay CR, Chandraratna PA, Kawanishi DT, Rahimtoola SH. Mechanisms of increase in mitral valve area and influence of anatomic features in double-balloon, catheter balloon valvuloplasty in adults with rheumatic mitral stenosis: a Doppler and two-dimensional echocardiographic study. Circulation. 1987;76(3):628-636. Available from: https: //dx.doi.org/10.1161/01.cir.76.3.628.
21. Kaplan JD, Isner JM, Karas RH. In vitro analysis of balloon valvuloplasty of stenotic mitral valves. Am J Cardiol. 1987;59:318-341.

22. Fatkin D, Roy P, Morgan JJ, Feneley MP. Percutaneous balloon mitral valvotomy with the Inoue single-balloon catheter: Commissural morphology as a determinant of outcome. J Am Coll Cardiol. 1993;21(2):390-397. Available from: https: //dx.doi.org/10.1016/0735-1097(93)90680-y.

23. Wang J, Choo DCA, Zhang X, Yang Q, Xian T, Lu D, et al. The effect of transient balloon occlusion of the mitral valve on left atrial appendage blood flow velocity and spontaneous echo contrast. Clin Cardiol. 2000;23(7):501-506. Available from: https://dx.doi.org/10.1002/clc.4960230708.

24. Chien S, Kung-Ming J. Ultrasound basis of the mechanism of rouleaux formation. Microvasc Res. 1973;5:155-66.

25. Merino A, Hauptman P, Badimon L, Badimon JJ, Cohen M, Fuster V, et al. Echocardiographic "smoke" is produced by an interaction of erythrocytes and plasma proteins modulated by shear forces. J Am Coll Cardiol. 1992;20(7):1661-1668. Available from: https://dx.doi.org/10.1016/0735-1097(92)90463-w.

26. Fatkin D, Loupas T, Low J, Feneley M. Inhibition of Red Cell Aggregation Prevents Spontaneous Echocardiographic Contrast Formation in Human Blood. Circulation. 1997;96(3):889896. Available from: https://dx.doi.org/10.1161/01.cir.96.3. 889.

27. Sadanandan S, Sherrid MV. Clinical and echocardiographic characteristics of left atrial spontaneous echo contrast in sinus rhythm. J Am Coll Cardiol. 2000;35(7):1932-1938. Available from: https://dx.doi.org/10.1016/s0735-1097(00)00643-4.

28. Bernstein NE, Demopoulos LA, Tunick PA, Rosenzweig BP, Kronzon I. Correlates of spontaneous echo contrast in patients with mitral stenosis and normal sinus rhythm. Am Heart J. 1994;128(2):287-292. Available from: https://dx.doi.org/10. 1016/0002-8703(94)90481-2.

29. Kasliwal RR, Mittal S, Kanojia A, Singh RP, Prakash O, Bhatia ML, et al. A study of spontaneous echo contrast in patients with rheumatic mitral stenosis and normal sinus rhythm: an Indian perspective. Heart. 1995;74(3):296-299. Available from: https://dx.doi.org/10.1136/hrt.74.3.296.

30. Karakaya O, Turkmen M, Bitigen A, Saglam M, Barutcu I, Esen AM, et al. Effect of Percutaneous Mitral Balloon Valvuloplasty on Left Atrial Appendage Function: A Doppler Tissue Study. J Am Soc Echocardiogr. 2006;19(4):434-437. Available from: https://dx.doi.org/10.1016/j.echo.2005.10.022.

31. Vijayvergiya R, Sharma R, Shetty R, Subramaniyan A, Karna S, Chongtham D. Effect of Percutaneous Transvenous Mitral Commissurotomy on Left Atrial Appendage Function: An Immediate and 6-Month Follow-Up Transesophageal Doppler Study. J Am Soc Echocardiog. 2011;24(11):1260-1267. Available from: https://dx.doi.org/10.1016/j.echo.2011.07.015.

32. Porte JM, Cormier B, Iung B, Dadez E, Starkman C, Nallet O, et al. Early assessment by transesophageal echocardiography of left atrial appendage function after percutaneous mitral commissurotomy. Am J Cardiol. 1996;77(1):72-76. Available from: https://dx.doi.org/10.1016/s0002-9149(97)89137-0. 
Copyright: (C) the author(s), 2020. It is an open-access article distributed under the terms of the Creative Commons Attribution License (CC BY 4.0), which permits authors to retain ownership of the copyright for their content, and allow anyone to download, reuse, reprint, modify, distribute and/or copy the content as long as the original authors and source are cited.

How to cite this article: Kumar A S, Magesh B . Left Atrial Appendage (LAA) Function by Transesophageal Echocardiography before and after Percutaneous Balloon Mitral Valvuloplasty (PBMV)- A Comparative Study. Acad. J Med. 2020;3(1):64-69.

DOI: dx.doi.org/10.47008/ajm.2020.3.1.13

Source of Support: Nil, Conflict of Interest: None declared. 